\title{
Compliance with follow-up for patients with stage 1 testicular germ cell tumour
}

\author{
Authors: Cheung $\mathrm{KT}^{1}$, Dat $\mathrm{A}^{1}$, Wong $\mathrm{P}^{1}$, Dowling $\mathrm{C}^{1,2}$, Davis $\mathrm{ID}^{2,3}$, Sengupta $\mathrm{S}^{1,2,4}$ \\ 1 Department of Urology, Eastern Health, Box Hill, Victoria, Australia \\ 2 Eastern Health Clinical School, Monash University, Box Hill, Victoria, Australia \\ 3 Department of Oncology, Eastern Health, Box Hill, Victoria, Australia \\ 4 Department of Surgery, University of Melbourne, Heidelberg, Victoria, Australia
}

\section{Correspondence to:}

Professor Shomik Sengupta

Eastern Health Clinical School, Monash University

Level 2, 5 Arnold Street, Box Hill, Victoria 3128, AUSTRALIA

T: (613) 90949546 F: (613) 98999137

E: shomik.sengupta@monash.edu

This is the author manuscript accepted for publication and has undergone full peer review but has not been through the copyediting, typesetting, pagination and proofreading process, which may lead to differences between this version and the Version of Record. Please cite this article as doi: $10.1111 /$ ans.16114

This article is protected by copyright. All rights reserved. 


\begin{abstract}
Background: To evaluate the compliance and loss-to-follow-up (LTFU) rate in patients with stage 1 testicular germ cell tumours (GCTs) on active surveillance protocol at a metropolitan health service in Melbourne, Australia.
\end{abstract}

Methods: Patients with stage 1 testicular GCTs between 30th June 2012 and 30th June 2018 were identified. Compliance of surveillance program was classified into three groups: 'adequate', 'missed appointment(s)' or 'loss-to-follow-up (LTFU)'. The LTFU rate was assessed using Kaplan Meier methodology plots. Log-rank test was used for univariate analyses.

Results: Forty-eight patients had stage 1 testicular GCTs during the 6-year period. 22(46\%) of them were managed with active surveillance and 26(54\%) of them were given adjuvant therapy. Compliance with active surveillance was assessed as 'adequate' in 12 (55\%), 'missed appointment(s)' in 6 (27\%), and 'loss-to-follow-up' in 4 (18\%). The LTFU rates in patients with active surveillance at 12, 24, 36 months were $9 \%, 9 \%$ and $19 \%$ respectively. The LTFU rate in patients with active surveillance was not significantly different from patients who received adjuvant therapy. (Hazard Ratio (HR): 0.71[95\% confidence intervals $0.22,2.30],=0.56)$ Three $(14 \%)$ of 22 patients managed with active surveillance had recurrence of disease, all of which occurred in the first 12 months, compared to two (8\%) of 26 patients who had adjuvant therapy.

Conclusion: Active surveillance is a commonly utilised management option for stage 1 testicular germ cell tumours, but has a loss-to-follow-up rate of almost $20 \%$ that may limit its effectiveness. The recurrence rate was comparable to published literature. 
Keyword: Urology, Surgical Oncology.

\section{Introduction}

Testicular cancer is the most common cancer in young men, with the majority of patients diagnosed between the ages of 20 and 34. [1] In Australia, it accounts for approximately $1.2 \%$ of all cancer in men. [2] Histologically, testicular germ cell tumours (GCTs) are sub-classified into two main types: seminoma and non-seminoma (NSGCT). Patients commonly present with stage 1 disease. [1]

Currently, there are several acceptable management options for stage 1 testicular GCTs after radical inguinal orchidectomy, depending on disease characteristics. [3-7]. For stage 1 seminoma, this includes active surveillance, adjuvant chemotherapy usually involving single-dose carboplatin, or radiation therapy although use of radiation is diminishing due to concerns regarding late toxicity. For stage 1 NSGCT, management choices include surveillance with a view to salvage treatment for those who relapse, adjuvant chemotherapy using a combination of Bleomycin, Etoposide and cisplatin, and/or primary retroperitoneal lymph node dissection. Adjuvant chemotherapy and RPLND are both used relatively infrequently in Australia. Each of these strategies has been proven effective, with 5-year survival rates ranging between 98 to $100 \%$. [8]

Given its efficacy and potential to avoid unnecessary treatments, active surveillance has been recommended as the preferred option for stage 1 testicular GCTs by many international guidelines. [9-12] However, according to a survey of Australian oncologists by Grimison et al in 2010, only 33\% and $73 \%$ of patients with seminoma and non-seminoma, respectively, were managed with active surveillance. [13] Successful implementation depends on compliance with the active surveillance protocol, which includes regular outpatient visits, blood tests and CT scans. Anxiety about recurrence is also a factor that drives patients away from active surveillance. [14]

This article is protected by copyright. All rights reserved. 
In this study, we aimed to evaluate the compliance and loss-to-follow-up (LTFU) rate for patients with stage 1 testicular GCTs on active surveillance at our institution.

\section{Methods}

With institutional ethics approval, all orchidectomies performed at our institution between 30th June 2012 and 30th June 2018 was identified. A database was created for patients with stage 1 seminoma or non-seminoma GCT based on formal histology and radiology reports. Clinical variables included in the database were age at orchidectomy, date of first and last outpatient clinic visit postorchidectomy, management options (active surveillance/ adjuvant therapy), and recurrence. Observation period of a patient starts on the date of their first outpatient clinic visit post-orchidectomy and ends at the date of his last visit before 30th June 2018.

Compliance of a patient was classified into three groups: 'adequate', 'missed appointment(s)' or 'loss to follow up (LTFU)'. Adequate compliance means that the patient attended all relevant scheduled outpatient clinic appointments. Patients in the 'Missed appointment(s)' group had missed at least 1 or more appointment(s) during the observation period but were still under follow-up. 'LTFU' Patients were the ones who failed to attend within 2 months of their most recent scheduled appointment despite at least 2 phone and mail reminders for re-scheduling.

The LTFU rate was assessed using Kaplan Meier methodology. Patients who had recurrence were censored at the date of recurrence. Log-rank test was used for univariate analyses. Statistical analyses were performed using STATA 15 (StataCorp. 2017. Stata Statistical Software: Release 15. College Station, TX: StataCorp LLC). In all tests, $p$ values were two-sided with a significance of less than $5 \%$ i.e. $p$ value $<0.05$

\section{Results}


48 patients were diagnosed with stage 1 testicular germ cell tumour at Eastern Health between 30th June 2012 and 30th June 2018. Twenty-two (46\%) were managed with active surveillance and 26 (54\%) were given adjuvant therapy. The number of patients under active surveillance with seminoma and non-seminoma GCT were 7 (32\%) \& 15 (68\%) respectively. The median age at diagnosis for patients with active surveillance and adjuvant therapy were $25.8[23.5,34.4]$ and $38.1[32.3,43.1]$ years old. The overall median duration of follow up 1.7 years.

$12(55 \%)$ of the 22 patients with active surveillance had adequate compliance. 6 (27\%) missed at least one appointment and the remaining $4(18 \%)$ were lost to follow up. The compliance of active surveillance by histology and age is shown in Table 1. Younger age group was not shown to have a higher LTFU rate than their older counterpart $(p$ value $=0.80$ ). No difference in LTFU rate was found between the two histology groups ( $p$ value $=0.91)$. The LTFU rates in patients with active surveillance, at 12, 24 and 36 months were $9 \%, 9 \%$ and 19\%, compared to $16 \%, 26 \%$ and $32 \%$ in patients with adjuvant therapy. The LTFU rates in these two groups of patients were not significantly different. (Figure 1; Hazard Ratio: $0.71[0.22,2.30], p=0.56)$

Three (14\%) of 22 patients managed with active surveillance had recurrence of disease, all of which occurred in the first 12 months, compared to two (8\%) of 26 patients who had adjuvant therapy.

\section{Discussion}

Our study demonstrated low but definable lack of compliance with active surveillance for patients with stage 1 testicular germ cell tumours. Most patients remained under active surveillance by the end of our 6-year observation period, with an overall loss to follow up rate of $18 \%$. Compliance with surveillance programs vary greatly across different health institutions. A multi-centre review showed that the compliance rates of patients with stage 1 non-seminoma GCTs in seven Canadian centres ranged from $68 \%$ to $94 \%$, with a median of $79 \%$. [15] In another Canadian study by Hao et al, $62 \%$ of patients were 
compliant to clinical appointments at 12 months; however, only 36\% remained compliant at 24 months. [16] A Sydney-based study in 2015 reported $12 \%$ of patients with stage 1 testicular GCTs were lost to follow up by the end of a 4-year period, similar to $18 \%$ of patients in our 6-year period. [17] LTFU rates at 12 and 24 months were also comparable to our study, which showed that $4 \%$ and $13 \%$ of their patients were lost to follow up at 12 and 24 months, respectively.

According to a large-cohort study in Japan in 2013, 14.2\% of patients with stage 1 seminoma was lost to follow up at 24 months, again comparable to our experience. [18] Similar to our analysis, LTFU rates were not found to be significantly different between patients managed with active surveillance and adjuvant therapy. This is somewhat surprising, since predicted compliance is one of the factors used to recommend patients for surveillance instead of active therapy, and hence compliance would have been predicted to be higher in the surveillance group. Younger age, although a risk factor in the Japanese study, was not associated with a higher LTFU rate in our study.

There were several other limitations in our study. Numbers were relatively small and follow up was short. Compliance has been defined differently between studies and interpretation might thus be biased. We adopted a definition similar to the Sydney-based study by Honeyball et al to minimise the inter-study differences. [17] Moreover, detailed compliance data such as CT scanning and blood tests was not included in our study. Patients who were followed up privately or at other health services due to traveling distance may have been missed in our data.

\section{Conclusion}

Active surveillance is a commonly utilised management option for stage 1 testicular germ cell tumours, but has a loss-to-follow-up rate of almost $20 \%$ that may limit its effectiveness. The recurrence rate was comparable to published literature, but adequate follow-up is essential to ensure that these patients can be successfully salvaged using chemotherapy. 
Acknowledgements:

IDD is supported by an NHMRC Practitioner Fellowship (APP1102604).

This article is protected by copyright. All rights reserved. 


\section{References}

1. Noone AM, H.N., Krapcho M, Miller D, Brest A, Yu M, Ruhl J, Tatalovich Z, Mariotto A, Lewis DR, Chen HS, Feuer EJ, Cronin KA (eds). SEER Cancer Statistics Review, 1975-2015, National Cancer Institute. Bethesda, MD, https://seer.cancer.gov/csr/1975 2015/, based on November 2017 SEER data submission, posted to the SEER web site, April 2018.

2. Australian Institute of Health and Welfare (AlHW) 2017 Australian Cancer Incidence and Mortality (ACIM) books: testicular cancer Canberra: AlHW. <http://www.aihw.gov.au/acim-books>.

3. Cullen, M.H., et al., Short-course adjuvant chemotherapy in high-risk stage I nonseminomatous germ cell tumors of the testis: a Medical Research Council report. J Clin Oncol, 1996. 14(4): p. 1106-13.

4. Gilbert, D.C., et al., Treating stage I nonseminomatous germ cell tumours with a single cycle of chemotherapy. BJU Int, 2006. 98(1): p. 67-9.

5. Hamilton, C., et al., Radiotherapy for stage I seminoma testis: results of treatment and complications. Radiother Oncol, 1986. 6(2): p. 115-20.

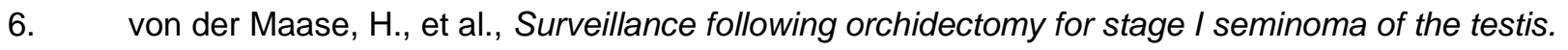
Eur J Cancer, 1993. 29a(14): p. 1931-4.

7. Mead, G.M., et al., Randomized trials in 2466 patients with stage I seminoma: patterns of relapse and follow-up. J Natl Cancer Inst, 2011. 103(3): p. 241-9.

8. Horwich, A., J. Shipley, and R. Huddart, Testicular germ-cell cancer. Lancet, 2006. 367(9512): p. 754-65.

9. National Comprehensive Cancer Network. Testicular cancer (version 1.2015), 2015 [cited 2014 Nov 13]. Available from URL: http://www.nccn.org/professionals/physician_gls/pdf/testicular.pdf

10. BC Cancer Agency. Management: pure seminomas and Nonseminomatous germ cell tumours (with or without seminoma), 2013 [cited 2014 Nov 13]. Available from URL:

This article is protected by copyright. All rights reserved. 
http://www.bccancer.bc.ca/health-professionals/professional-resources/cancermanagementguidelines/genitourinary/testis

11. Albers P, A.W., Algaba F, Bokemeyer C, Cohn-Cedermark G, Fizazi K et al. Guidelines on testicular cancer: update March 2011. European Association of Urology, pp. 13-18, 2011.

12. Australian and New Zealand Urogenital and Prostate (ANZUP) Cancer Trial Group (2018, August 20) ANZUP SURVEILLANCE RECOMMENDATIONS FOR METASTATIC TESTICULAR CANCER POST-CHEMOTHERAPY. Available from URL:

https://anzup.org.au/docview.aspx?id=880

13. Grimison, P., et al., Patterns of management and surveillance imaging amongst medical oncologists in Australia for stage I testicular cancer. BJU Int, 2013. 112(2): p. E35-43.

14. Groll, R.J., P. Warde, and M.A. Jewett, A comprehensive systematic review of testicular germ cell tumor surveillance. Crit Rev Oncol Hematol, 2007. 64(3): p. 182-97.

15. Ernst, D.S., et al., Compliance and outcome of patients with stage 1 non-seminomatous germ cell tumors (NSGCT) managed with surveillance programs in seven Canadian centres. Can J Urol, 2005. 12(2): p. 2575-80.

16. Hao, D., et al., Compliance of clinical stage I nonseminomatous germ cell tumor patients with surveillance. J Urol, 1998. 160(3 Pt 1): p. 768-71.

17. Honeyball, F., et al., Compliance of males with stage 1 testicular germ cell tumours on an active surveillance protocol. Intern Med J, 2015. 45(10): p. 1081-4.

18. Endo, T., et al., Risk factors for loss to follow-up during active surveillance of patients with Stage I seminoma. Jpn J Clin Oncol, 2014. 44(4): p. 355-9.

This article is protected by copyright. All rights reserved. 


\section{Table Legend}

Table 1. Compliance of patients on active surveillance $(n=22)$

\section{Figure Legends}

Figure 1. Loss-to-follow-up (LTFU) over time in patients managed by active surveillance and adjuvant therapy. $(p$-value $=0.56)$

This article is protected by copyright. All rights reserved. 


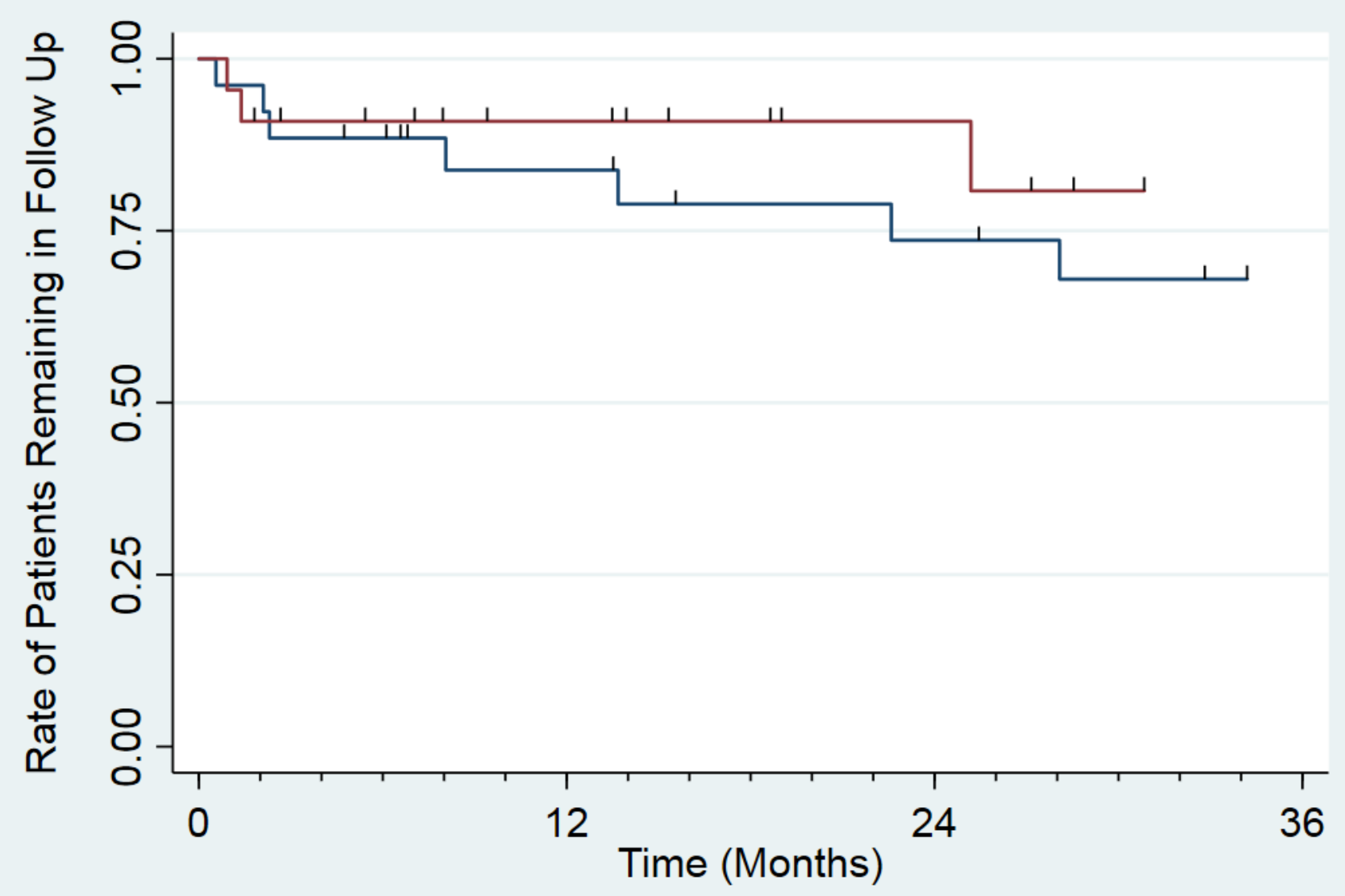

Number at risk

Adjuvant Therapy 26 Active Surveillance 22
18

14
14

9
10

5

ANS_16114_Figure 1. Loss-to-follow-up (LTFU) over time in patients managed by active surveillance and adjuvant therapy. (p-value $=0.56)$ FINAL.tif 
Table 1. Compliance of patients on active surveillance $(n=22)$

\begin{tabular}{lccc}
\hline & Adequate & Missed 1+ appointment (s) & Lost to Follow Up \\
All patients & $12(55 \%)$ & $6(27 \%)$ & $4(18 \%)$ \\
By Histology & & & \\
Seminoma & $3(43 \%)$ & $3(43 \%)$ & $1(14 \%)$ \\
Non-seminoma GCT & $9(60 \%)$ & $3(20 \%)$ & $3(20 \%)$ \\
By Age at diagnosis & $4(40 \%)$ & $4(40 \%)$ & $2(20 \%)$ \\
26 & $8(66 \%)$ & $2(17 \%)$ & $2(17 \%)$
\end{tabular}

${ }^{*} p$ value: log-rank test for lost to follow up 


\section{University Library}

\section{- M M N E R VA A gateway to Melbourne's research publications}

Minerva Access is the Institutional Repository of The University of Melbourne

\section{Author/s:}

Cheung, KT;Dat, A;Wong, P;Dowling, C;Davis, ID;Sengupta, S

Title:

Compliance with follow-up for patients with stage 1 testicular germ cell tumour

Date:

2020-07-02

Citation:

Cheung, K. T., Dat, A., Wong, P., Dowling, C., Davis, I. D. \& Sengupta, S. (2020). Compliance with follow-up for patients with stage 1 testicular germ cell tumour. ANZ JOURNAL OF SURGERY, 91 (1-2), pp.184-186. https://doi.org/10.1111/ans.16114.

Persistent Link:

http://hdl.handle.net/11343/275976 